\title{
Hemispheric Dissociation of the Involvement of NOS Isoforms in Memory for Discriminated Avoidance in the Chick
}

\author{
Nikki S. Rickard ${ }^{1,3}$ and Marie E. Gibbs ${ }^{2}$ \\ ${ }^{1}$ Department of Psychology, Monash University, Victoria 3145, Australia; ${ }^{2}$ Department of Pharmacology, Monash \\ University, Clayton 3800, Australia
}

\begin{abstract}
Previous research has indicated a role for both the neuronal (nNOS) and endothelial (eNOS) nitric oxide isoforms in memory formation. In addition, two distinct periods of activity of nitric oxide activity, dissociated by hemispheric localization, are implicated following passive avoidance training in the chick. In the present study, we trained black Australorp-white Leghorn chicks on a color discrimination avoidance task. Diphenyleneiodonium chloride $(1 \mu \mathrm{M})$ or $N$-propyl-L-arginine $(50 \mu \mathrm{M})$ was administered into either the left or right hemisphere of the chick brain in an attempt to differentiate the effects of inhibiting eNOS or nNOS, respectively. The memory loss previously observed following administration of diphenyleneiodonium chloride between 10 and 20 min posttraining was found to be lateralized to the right hemisphere, although administration of this agent into the left hemisphere around the time of training was also amnestic. In contrast, $N$-propyl-L-arginine caused memory loss only when administered to the left hemisphere around the time of training. These findings suggest that activation of both eNOS and nNOS isoforms may be essential for long-term memory consolidation of this task. Further, these two periods of activity are defined temporally and by hemisphere localization, although confirmation with more selective inhibitors when they become available is advised.
\end{abstract}

The free radical gas nitric oxide has been implicated in several forms of learning and memory, as well as in several forms of synaptic plasticity thought to underlie memory formation (for reviews, see Hölscher 1997; Hawkins et al. 1998; Prast and Philippu 2001). This has been widely demonstrated via pharmacological studies which utilize a variety of inhibitors of the enzyme responsible for the synthesis of nitric oxide, nitric oxide synthase (NOS). There are three isoforms of NOS: the neuronal form (nNOS or Type I), the inducible form (iNOS or Type II), and the endothelial form (eNOS or Type III). Studies of knockout mice revealed that mice doubly deficient in expression of eNOS and nNOS exhibit impaired long-term potentiation (LTP). In contrast, single mutant mice retain the capacity for normal LTP (O'Dell et al. 1994; Son et al. 1996), suggesting that either isoform is sufficient for this putative mechanism of memory formation. Interestingly, mice deficient for the eNOS gene are superior in water maze performance (Frisch et al. 2000), but no different from their controls on radial maze performance (Dere et al. 2001), suggesting that NOS requirements may vary across tasks. Although the majority of pharmacobehavioral studies demonstrating a role for nitric oxide in learning or memory have used general NOS inhibitors, there is some evidence that implicates specific isoforms in memory processing.

7-nitroindazole (7-NI) is regarded as a specific inhibitor of $\mathrm{nNOS}$ at doses between 20 and $80 \mathrm{mg} / \mathrm{kg}$ i.p. (Moore et al. 1993), although in vitro, 7NI also potently inhibits eNOS (Bland-Ward et al. 1994). Systemic administration of 7-NI at doses within this range have been found to inhibit spatial learning. Meyer et al. (1998) found that spatial learning was significantly impaired in 3-4-mo-old male rats by administration of $65 \mathrm{mg} / \mathrm{kg}$ 7-NI $30 \mathrm{~min}$ prior to training. Administration of 10 or $30 \mathrm{mg} / \mathrm{kg}$ 7-NI imme-

\section{${ }^{3}$ Corresponding author.}

E-MAIL n.rickard@med.monash.edu.au; FAX 61-3-9903-2501.

Article and publication are at http://www.learnmem.org/cgi/doi/10.1101/ Im.59503. diately after object discrimination training impaired recall in 3-mo-old male Tryon-Maze-Bright rats $1 \mathrm{~h}$ after training (Prickaerts et al. 1997). It was noted, however, that the higher dose did in fact increase mean arterial blood pressure in these rats, indicating that eNOS may also have been inhibited by 7-NI. Administration of $30 \mathrm{mg} / \mathrm{kg} 7-\mathrm{NI}$ to male rats $30 \mathrm{~min}$ prior to training impaired both working and reference memory for a spatial learning task (Hölscher et al. 1995), although in another study, administration of either 25 or $50 \mathrm{mg} / \mathrm{kg}$ 7-NI to 2-mo-old male rats before training was found to impair only reference memory (Zou et al. 1998). Finally, administration of $50 \mathrm{mg} / \mathrm{kg} 7-\mathrm{NI} 1 \mathrm{~h}$ prior to passive avoidance training in 1-d-old chicks impaired recall when tested $30 \mathrm{~min}, 2 \mathrm{~h}$, and $24 \mathrm{~h}$ (but not $5 \mathrm{~min}$ ) later (Hölscher 1994). In the latter study, potential side effects of NOS inhibition on general performance (including motor skills and orientation) were excluded in separate experiments (see also Hölscher et al. 1995). Despite some inconsistencies, the majority of previous research therefore suggests that blocking nNOS impairs longterm retention in young rats and chicks. However, in each of these studies, 7-NI was administered peripherally, and in the majority, prior to training. The findings must, therefore, be interpreted with caution given the potential for nonspecific effects of the drug during acquisition of the task, particularly in the rodent tasks, which did not typically control for the nonspecific effects of NOS inhibition on general performance.

In contrast, Rickard et al. (1999) found that bilateral intracranial administration of three other inhibitors of nNOS, S-methyl-l-thiocitrulline (SMTC), N-propyl-l-arginine (NPLA), and 3-bromo-7-nitroindazole (BNI) to day-old chicks had no effect on memory when administered $1 \mathrm{~h}$ before training on a discrimination passive avoidance task. In addition, administration of NPLA $(10 \mathrm{nM}-100 \mu \mathrm{M}) 5 \mathrm{~min}$ posttraining was also without effect on memory for this task. Unlike the previous research with 7-NI, these drugs were administered directly into a region of the brain implicated in memory for this task, and thus nonspe- 
cific effects arising from peripheral administration are not possible. Given that each of these inhibitors has also been reported to be more selective for nNOS in vitro than is 7-NI, these findings cast some doubt on whether nNOS inhibition actually impairs learning. Alternatively, differences in species, task, drug type and breakdown rates, dose, and route of administration may account for these inconsistencies (see, e.g., Hölscher 2002), and a more systematic investigation of specific nNOS inhibition on memory is required before any conclusions can be drawn. In particular, the effect of intracranial injections given posttraining has not been sufficiently explored. In addition, the use of this passive avoidance task for the chick is advantageous over many other rodent tasks because the discrimination measure controls for many of the potential side-effects of NOS inhibition, such as anxiolysis and problems with motor coordination.

There is also limited evidence that inhibition of eNOS impairs some forms of memory formation. Rickard et al. (1999) demonstrated that administration of the iNOS and eNOS inhibitor diphenyleneiodonium chloride (DPI) impaired memory for the passive avoidance task in day-old chicks. This effect was dependent on the dose $(1-10 \mu \mathrm{M})$ and time of administration (5 to $20 \mathrm{~min}$ posttraining). When administered $5 \mathrm{~min}$ posttraining, DPI caused a persistent retention loss from $40 \mathrm{~min}$ posttraining. Pretraining injections of DPI, however, had no effect on retention, suggesting that DPI does not impair acquisition of the task. Further, administration of a specific iNOS inhibitor, 1400W, at this time had no effect on retention, suggesting that the effect of DPI was probably due to eNOS inhibition.

Interestingly, the effects of nonspecific NOS inhibition appear to be lateralized and localized. Rickard and Gibbs (2003) found that unilateral administration of $\mathrm{N}^{\omega}$-Nitro-L-arginine methyl ester (L-NAME) into the left hyperstriatal-neostriatal region of the chick brain impaired retention when administered only at $5 \mathrm{~min}$ prior to, immediately after, or $5 \mathrm{~min}$ after passive avoidance training. However, administration into the same region in the right hemisphere produced retention loss only when administered 15,20 , or 25 min posttraining. This hemispheric dissociation suggests that two quite different NOS-related processes may be triggered by passive avoidance training in the chick. It seems feasible then that some of the inconsistencies observed in previous research may be explained by specific NOS isoforms being activated in different hemispheres of the brain after learning. The aim of the present study, therefore, was to investigate whether the lateralized NOS activity required for memory formation for the discrimination passive avoidance task is also distinguished by NOS isoform.

\section{RESULTS}

\section{Experiment 1: Lateralization of Effective Times of DPI Administration}

The goal of Experiment 1 was to determine whether the amnestic effect of DPI previously observed (Rickard et al. 1999) was lateralized. Different groups (sample sizes from 17 to 20) of chicks were administered $1 \mu \mathrm{M}$ DPI unilaterally into either the left or right hemisphere. Each treatment was administered at various times between 5 min pretraining and 25 min posttraining, and all chicks were tested 120 min after training.

As shown in Figure 1, a significant time of administration by hemisphere interaction was observed $[F(6,248)=16.56, P<.001]$. Simple main effects analyses revealed that compared to right hemisphere-injected chicks, retention in left hemisphere-injected chicks was significantly lower when DPI was administered at 5 min pretraining $(P<.001)$ or immediately posttraining $(P<.001)$, and significantly higher when DPI was administered

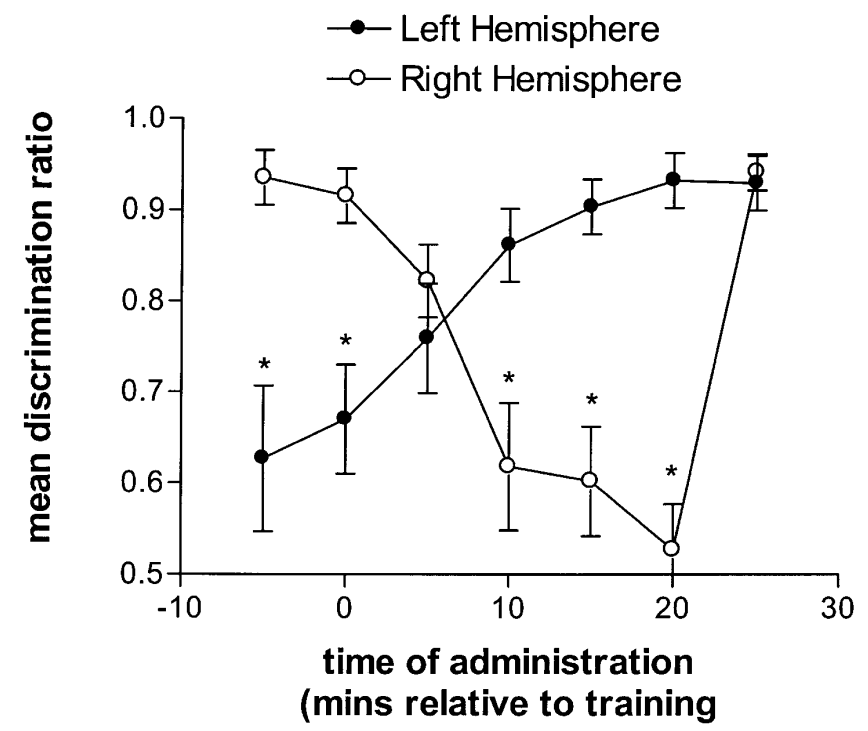

Figure 1 Retention tested at 120 min after training following unilateral administration of $1 \mu \mathrm{M} \mathrm{DPI}$ into either the left or right hemisphere at various times posttraining. ${ }^{*} P<.05$.

at 10 min posttraining $(P<.005), 15$ min posttraining $(P<.001)$, or 20 min posttraining $(P<.001)$.

\section{Experiment 2: Dose Response Study of nNOS Inhibitor, NPLA}

Our previous data indicated that inhibition of nNOS had no effect on memory when the inhibitor was administered $1 \mathrm{~h}$ prior to training or 5 min posttraining (Rickard et al. 1999). Nonetheless, studies with rats have shown an effect of 7-NI when administered 30 min before (Hölscher et al. 1995; Meyer et al. 1998) or 'after' training (Prickaerts et al. 1997). The aim in Experiment 2 was to systematically explore the effects of posttraining administration for a wider range of doses of a specific nNOS inhibitor. Different groups of chicks (sample sizes 18-20) were administered $1 \mu \mathrm{M}$ DPI bilaterally at various times relative to training, and retention was tested $120 \mathrm{~min}$ posttraining. The effective times of administration would then be explored for any effective dose of NPLA.

Bilateral administration of NPLA was found to impair retention in a dose-dependent fashion, with 50 and $100 \mu \mathrm{M}$ being the most effective concentrations (Fig. 2A). A one-way ANOVA confirmed a significant concentration effect, $F(4,89)=7.28, P<.001$, with post-hoc Dunnett's tests showing that retention levels of chicks administered $30 \mu \mathrm{M}(P<.005), 50 \mu \mathrm{M}(P<.001)$, or 100 $\mu \mathrm{M}(P<.001)$ at $2.5 \mathrm{~min}$ posttraining were significantly lower than those of chicks administered saline at the same timepoints. The amnestic effect of $50 \mu \mathrm{M}$ NPLA was also found to be dependent on time of administration (Fig. 2B), when different groups of chicks (sample sizes 18-20) were administered the drug at different times relative to training. A one-way ANOVA revealed a significant time of administration effect, $F(9,176)=7.44$, $P<.001$, with post-hoc Dunnett's tests revealing that retention levels of chicks administered NPLA at 5 min pretraining $(P<.005)$, immediately after training $(P<.01)$, or 2.5 min posttraining $(P<.005)$ were significantly lower than those of chicks administered saline at 2.5 min posttraining.

\section{Experiment 3: Lateralization of Effective Times of NPLA Administration}

The aim of Experiment 3 was to determine whether the effect of NPLA was lateralized, and at what time any memory loss began. 
A

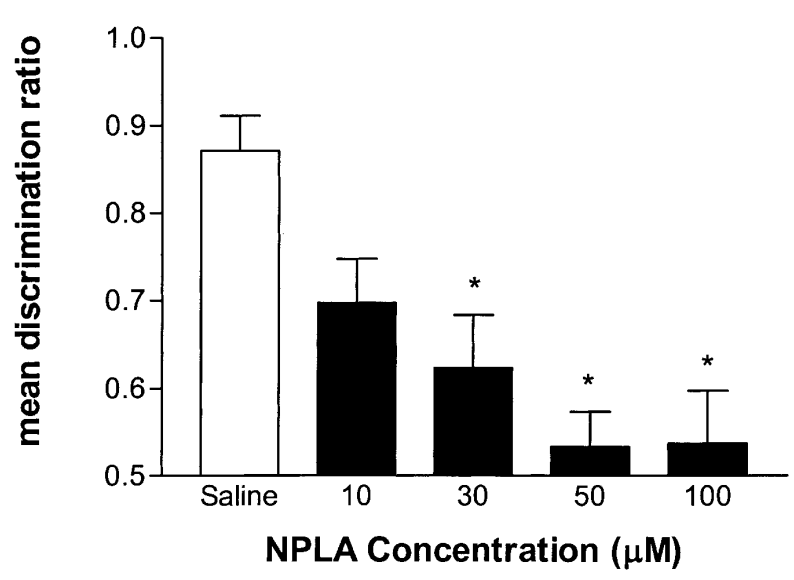

B

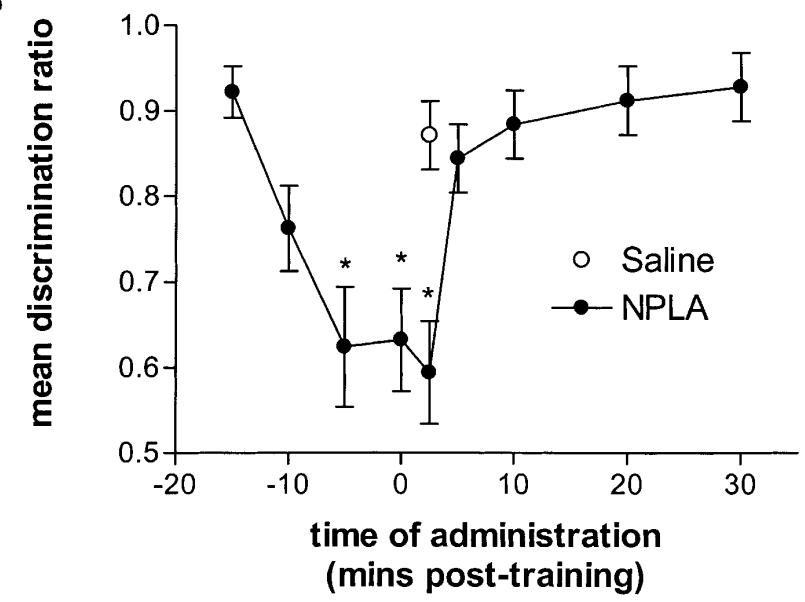

Figure 2 Retention tested at $120 \mathrm{~min}$ after training following bilateral administration of $(A)$ various concentrations of NPLA 2.5 min posttraining; (B) $50 \mu \mathrm{M}$ NPLA at various times before and after training. (Control saline group in both studies was administered 2.5 min posttraining, and tested 120 min after training.) ${ }^{*} P<.05$.

Different groups of chicks (sample sizes 16-20) were administered $50 \mu \mathrm{M}$ NPLA into either the left or right hemisphere at 5 min prior to, or 2.5 or 5 min after training, and retention was tested 120 min posttraining.

Unilateral administration of $50 \mu \mathrm{M}$ NPLA caused retention loss 120 min posttraining when administered into the left hemisphere at $5 \mathrm{~min}$ before or $2.5 \mathrm{~min}$ after training (Fig. 3A). Unilateral administration of NPLA into the right hemisphere at any of the times tested had no significant effect on retention. A two-way ANOVA confirmed a significant interaction effect, $F(2,107)=14.99, P<.001$, with simple main effects post-hoc analyses revealing that retention levels of chicks administered NPLA in the left hemisphere at 5 min before $(P<.001)$ and 2.5 min after $(P<.001)$ training were significantly lower than those of chicks administered NPLA in the right hemisphere at the same timepoints.

Chicks were then administered NPLA into the left hemisphere $2.5 \mathrm{~min}$ posttraining, and retention was tested at various times between 30 and 120 min posttraining (sample sizes 16-20). Retention levels were significantly lower in NPLA-treated chicks compared to those of chicks administered saline from $50 \mathrm{~min}$ posttraining onwards (Fig. 3B). A one-way ANOVA revealed a significant time of test effect, $F(9,175)=7.72, P<.001)$. Post-hoc Dunnett's confirmed that mean discrimination ratios of chicks administered NPLA were lower than those of the saline control group at all times tested after 40 min posttraining $(P<.05)$.

\section{DISCUSSION}

Previous findings in our laboratory indicated that memory for the passive avoidance task could be impaired by blockade of two distinct periods of NOS activity. Injection of the nonspecific inhibitor, L-NAME, into the left intermediate medial hyperstriatum ventrale (IMHV) around the time of training or into the right IMHV some 10 to 20 min later, significantly impaired retention (Rickard and Gibbs 2003). Our present data extend these findings by clarifying the type of NOS activity that may underlie these lateralized effects (Table 1).

In the present study, administration of either DPI or NPLA into the left hemisphere impaired retention from 40 min posttraining, provided injections were given around the time of training. These temporal parameters are entirely consistent with our previous findings when a general inhibitor of NOS activity was administered into the left hemisphere (Rickard and Gibbs 2003). The present data may indicate that both eNOS and nNOS must be available in the left hemisphere to produce NO at this time. This finding is notable for two reasons. First, it is consistent with
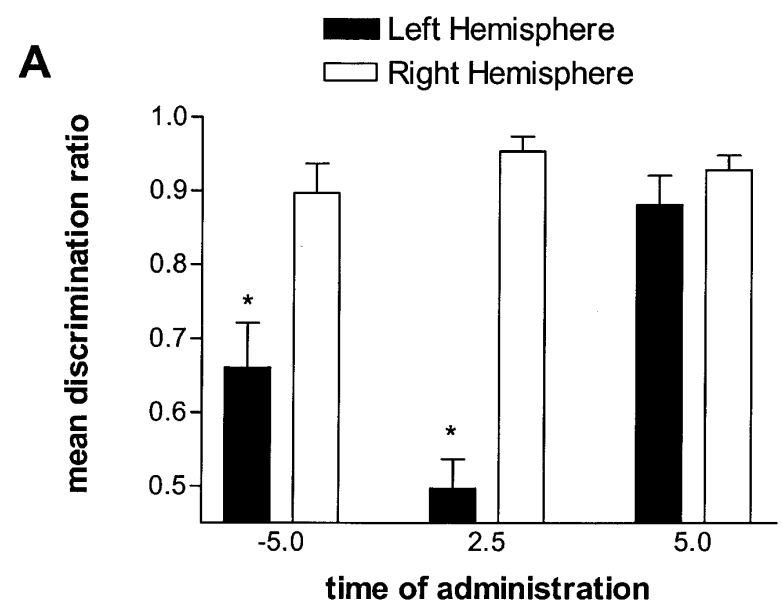

B (mins relative to training)

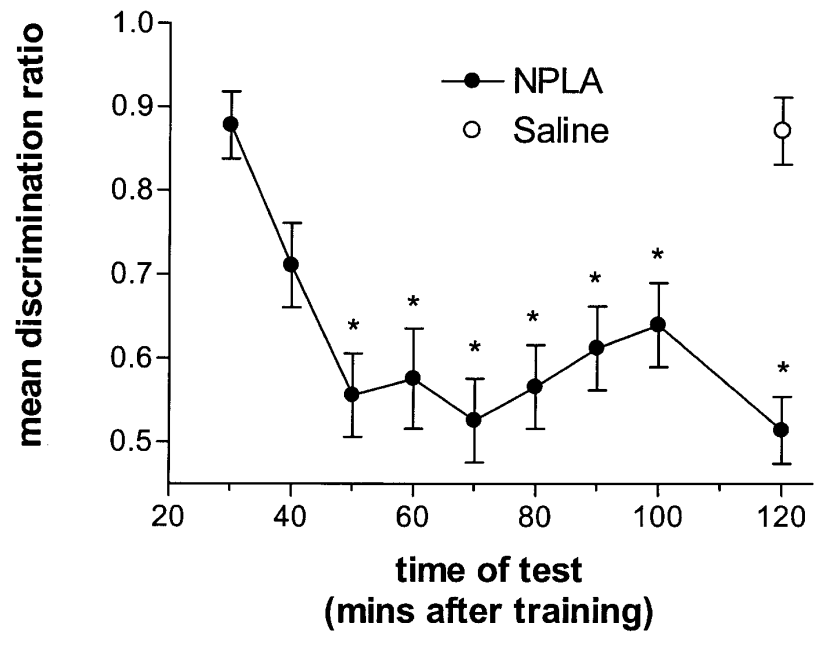

Figure 3 The effect of unilateral administration of $50 \mu \mathrm{M}$ NPLA into: $(A)$ the left or right hemisphere at $5 \mathrm{~min}$ pretraining, or 2.5 or $5 \mathrm{~min}$ after training, with retention tested at 120 min posttraining; or $(B)$ the left hemisphere at $2.5 \mathrm{~min}$ posttraining and tested at various times posttraining (control saline group was tested 120 min posttraining). ${ }^{*} P<.05$. 
Table 1. Summary of Times at Which General or Specific NOS Inhibitors Must Be Administered to Produce Memory Loss for the Discrimination Passive Avoidance Task

\begin{tabular}{|c|c|c|c|}
\hline & \multirow[b]{2}{*}{$\begin{array}{l}\text { Inhibition of } \\
\text { NOS isoform }\end{array}$} & \multicolumn{2}{|c|}{ Effective administration time } \\
\hline & & $\begin{array}{c}\text { Left } \\
\text { hemisphere } \\
\text { injection }\end{array}$ & $\begin{array}{c}\text { Right } \\
\text { hemisphere } \\
\text { injection }\end{array}$ \\
\hline $\begin{array}{l}\text { L-NAME } \\
\text { DPI } \\
\text { NPLA }\end{array}$ & $\begin{array}{l}\text { All (nNOS, eNOS, iNOS) } \\
\text { eNOS = iNOS } \\
\text { nNOS >> eNOS }\end{array}$ & $\begin{array}{l}-5,0,5 \mathrm{~m}+ \\
-5,0 \mathrm{~m}+ \\
-5,0,2.5 \mathrm{~m}+\end{array}$ & $\begin{array}{l}15,20,25 \mathrm{~m}+ \\
10,15,20 \mathrm{~m}+ \\
\text { No effect }\end{array}$ \\
\hline
\end{tabular}

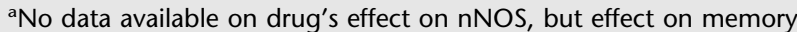
unlikely to be due to iNOS (Rickard et al. 1999).

previous observations that disruption of left hemisphere functions around the time of training impairs memory for this task (Gilbert et al. 1991; Gibbs et al. 2003). The present findings therefore provide further support that critical mechanisms for memory formation are activated in the left hemisphere very soon after learning. Second, the suggestion that both eNOS and nNOS activity may be necessary for memory formation is intriguing. Production of LTP in rodents, in contrast, requires activation of either NOS isoform, but not both (Son et al. 1996). Unfortunately, there is a lack of information regarding the effects of DPI on nNOS. However, given that posttraining injections of DPI into the right hemisphere impaired retention, it is unlikely that the effect of DPI can be attributed to any effect on nNOS, because posttraining injections of NPLA (which specifically block nNOS) had no effect on retention. It remains possible that the effects of DPI are due to iNOS inhibition, although this would seem unlikely given that we have previously shown that specific inhibition of iNOS at $5 \mathrm{~min}$ posttraining has no effect on retention for this task (Rickard et al. 1999). The effect of DPI in the left hemisphere around the time of training must, therefore, be interpreted with caution until more specific eNOS inhibitors become available.

Unfortunately, incomplete knowledge regarding selective NOS inhibitors also limits the confidence with which the conclusions regarding nNOS can be made. Despite being a highly selective nNOS inhibitor in vitro, and even meeting the conservative recommendation that an inhibitor only be considered 'selective' when its potency ratio is at least 100:1 (Moore and Handy 1997), comparable selectivity in vivo has not yet been ascertained. Nonetheless, as "by this criterion there is no known selective neuronal NOS (nNOS) inhibitor" (Moore and Handy 1997, p. 209), the present findings with NPLA can be considered among the most specific with regard to memory to date.

In contrast to findings in the left hemisphere, administration of inhibitors of eNOS or general NOS activity into the right hemisphere causes memory loss only if administered at times between 10 and 25 min posttraining. Specific inhibition of nNOS activity in the right hemisphere appears to have no effect on memory for this task, suggesting that this later NO-related activity is specific to eNOS. It is possible that this second phase of NOS activity relates to cerebral vasodilation, or some other mechanism more typically mediated by eNOS than nNOS. Interestingly, memory formation for the passive avoidance task in chicks appears to be most strongly dependent on processes activated in the left hemisphere, with the right hemisphere recruited largely for intermediate memory processes (i.e., between 15 and 55 min after training; Gibbs et al. 2003). One process strongly implicated in this stage of memory formation is glycolysis (and glycogenolysis), which is considered to be essential for providing the ad- ditional energy requirements during memory consolidation (O'Dowd et al. 1994a,b). Although clearly no conclusions can be drawn from the present data, it could be speculated that eNOS activity is also required at this time to enhance blood flow and thus glucose and oxygen to the brain regions actively involved in consolidation processes.

Regardless of when NOS activity is inhibited, or by which inhibitor, the effect on memory is the same. Memory loss occurs around 40 min posttraining, which corresponds to an intermediate stage (Phase B) of memory formation within the Gibbs-Ng model for this task and species (Ng and Gibbs 1991). Formation of this phase of memory is thought to be critical for long-term consolidation of memory ( $\mathrm{Ng}$ and Gibbs 1991), and we have demonstrated that two distinct periods of NOS activity are essential to establish this phase. Taken together with previous findings (Rickard et al. 1999), these periods of activity appear to be at least partially differentiated by isoform type and hemispheric localization. That is, nNOS (and possibly eNOS as well) is activated around the time of training in the left hemisphere, whereas eNOS is activated some 10-25 min later in the right hemisphere. These findings can be stated with some confidence given that the passive avoidance task used overcomes some of the limitations of other tasks used in NOS inhibition studies. Nonetheless, these findings are not necessarily generalizable to non-avian species, given the significant neuroanatomical and neurochemical differences across species. It is also important that the conclusions regarding the involvement in memory of eNOS, in particular, are confirmed once more selective inhibitors become available.

\section{MATERIALS AND METHODS}

One- to two-day-old black Australorp-white Leghorn cross cockerels were obtained from a local hatchery (Research Poultry Farm, Victoria). Eggs were exposed to light for a brief period $\sim 4 \mathrm{~d}$ before hatching, which is important for the lateralization of the developing chick brain (Rogers and Deng 1999). The single-trial color discrimination passive avoidance task has been described elsewhere in detail ( $\mathrm{Ng}$ and Gibbs 1991; Gibbs et al. 2003). Briefly, chicks were trained with a small red glass bead (4-mm dia.) coated with the taste aversant, methylanthranilate (MeA). The single training trial was $10 \mathrm{sec}$ in duration, and chicks which did not peck the bead during this time and demonstrate that they had tasted the aversant were excluded from data analysis. Retention tests were performed at various training-test intervals, and consisted of a 10-sec presentation of a dry red bead, followed by a dry blue bead. The number of pecks at each bead during the 10 -sec test trial was recorded using a hand-held recorder. Any chicks that failed to peck the control (blue) bead were excluded from the data analysis, providing a control for nonspecific avoidance. A different group of 20 chicks was used initially for each data point, with up to $20 \%$ excluded from the data analyses for the above reasons. Memory was indexed by a discrimination ratio which was calculated as the number of pecks at the blue bead to the total number of pecks at both beads on the retention trial by each chick. This means of operationalizing retention provides a continuous measure with 0.5 representing equal pecking of both blue and red beads (and thus total loss of memory for the training experience) and 1.0 representing absolute avoidance of the red peck with continued pecking of the blue bead (and thus perfect memory for the training experience, while controlling for generalized avoidance). Statistical analyses were performed on the mean discrimination ratio for each group of chicks, enabling independent ANOVAs to be utilized. Although some data demonstrated heterogeneity of variances, this violation is not considered to be serious when sample sizes are relatively equal (Howell 2002).

N $\omega$-propyl-L-arginine (NPLA) and diphenyleneiodonium chloride (DPI) were obtained from Cayman Chemical. NPLA is a reversible and specific nNOS inhibitor in vitro. It appears to be highly specific for nNOS, showing considerably greater selectiv- 
ity for nNOS than eNOS (Zhang et al. 1997; Cooper et al. 2000), and greater selectivity and potency in vitro than other nNOS inhibitors such as 7-NI (Bland-Ward and Moore 1995). Pharmacological agents that specifically inhibit eNOS do not appear to be currently available. However, DPI is an irreversible inhibitor of eNOS and iNOS (Stuehr et al. 1991), with no reported effect on nNOS. We previously demonstrated that specific inhibition of iNOS administered 5 min posttraining has no effect on retention for this task (Rickard et al. 1999), and therefore the effect of $1 \mu \mathrm{M}$ DPI administered at this timepoint was inferred to be via eNOS. Drugs were made up on the morning of each experiment, and freehand intracranial injections were made using a Hamilton syringe fitted with a repeating dispenser which released $10 \mu \mathrm{L}$ per hemisphere. The hyperstriatal-neostriatal region of the chick brain was targeted using landmarks on the surface of the chick's cartilaginous skull and a stereotaxic chick brain atlas (Kuenzel and Masson 1988), and the depth was regulated by a stop fitted to the needle (27 gauge).

\section{ACKNOWLEDGMENTS}

This research was performed with the financial assistance of the Australian Research Council.

The publication costs of this article were defrayed in part by payment of page charges. This article must therefore be hereby marked "advertisement" in accordance with 18 USC section 1734 solely to indicate this fact.

\section{REFERENCES}

Bland-Ward, P.A. and Moore, P.K. 1995. 7-Nitro indazole derivatives are potent inhibitors of brain, endothelium and inducible isoforms of nitric oxide synthase. Life Sci. 57: PL131-135.

Bland-Ward, P.A., Pitcher, A., Wallace, P., Gaffen, Z., Babbedge, R.C., and Moore, P.K. 1994. Isoform selectivity of indazole-based nitric oxide synthase inhibitors. Brit. J. Pharmacol. 112: 351P.

Cooper, G.R., Mialkowski, K., and Wolff, D.J. 2000. Cellular and enzymatic studies of $\mathrm{N}^{\omega}$-propyl-L-arginine and S-ethyl-N-[4(trifluoromethyl)phenyl]isothiourea as reversible, slowly dissociating inhibitors selective for the neuronal nitric oxide synthase isoforms. Arch. Biochem. Biophys. 375: 183-194.

Dere, E., Frisch, C., De Souza Silva, M.A., Gödecke, A., Schrader, J., and Huston, J.P. 2001. Unaltered radial maze performance and brain acetylcholine of the endothelial nitric oxide synthase knockout mouse. Neurosci. 107: 561-570.

Frisch, C., Dere, E., De Souza Silva, M.A., Gödecke, A., Schrader, J., and Huston, J.P. 2000. Superior water maze performance and increase in fear-related behavior in the endothelial nitric oxide synthase deficient mouse together with monoamine changes in cerebellum and ventral striatum. J. Neurosci. 20: 6694-6700.

Gibbs, M.E., Andrew, R.J., and Ng, K.T. 2003. Hemispheric lateralization of memory stages for discriminated avoidance learning in the chick. Behav. Brain Res. 139: 157-165.

Gilbert, D.B., Patterson, T.A., and Rose, S.P.R. 1991. Dissociation of brain sites necessary for registration and storage of memory for a one-trial passive avoidance task in the chick. Behav. Neurosci. 105: 553-561.

Hawkins, R.D., Son, H., and Arancio, O. 1998. Nitric oxide as a retrograde messenger during long-term potentiation in hippocampus. Prog. Brain Res. 118: 155-172.

Hölscher, C. 1994. 7-nitro indazole, a neuron-specific nitric oxide synthase inhibitor, produces amnesia in the chick. Learn. Mem. 1: 213-216.

Hölscher, C. 1997. Nitric oxide, the enigmatic neuronal messenger: Its role in synaptic plasticity. Trends Neurosci. 21: 63-64.

Hölscher, C. 2002. Different strains of rats show different sensitivity to block of long-term potentiation by nitric oxide synthase inhibitors. Eur. J. Pharm. 457: 99-106.

Hölscher, C., McGlinchey, L., Anwyl, R., and Rowan, M.J. 1995. 7-Nitro indazole, a selective neuronal nitric oxide synthase inhibitor in vivo, impairs spatial learning in the rat. Learn. Mem. 2: 267-278.

Howell, D.C. 2002. Statistical Methods for Psychology. Duxbury Press, Pacific Grove, CA.

Kuenzel, W.J., and Masson, M. 1988. A stereotaxic atlas of the brain of the chick (Gallus domesticus). Johns Hopkins University Press, Baltimore, MD.

Meyer, R.C., Spangler, E.L., Patel, N., London, E.D., and Ingram, D.K. 1998. Impaired learning in rats in a 14-unit T-maze by 7-nitroindazole, a neuronal nitric oxide synthase inhibitor, is attenuated by the nitric oxide donor, molsidomine. Eur. J. Pharm. 341: $17-22$.

Moore, P.K., and Handy, R.L.C. 1997. Selective inhibitors of neuronal nitric oxide synthase-Is no NOS really good NOS for the nervous system? Trends Pharmacol. Sci. 18: 204-211.

Moore, P.K., Babbedge, R.C., Wallace, P., Gaffen, Z.A., and Hart, S.L. 1993. 7-Nitro indazole, an inhibitor of nitric oxide synthase, exhibits anti-nociceptive activity in the mouse without increasing blood pressure. Brit. J. of Pharm. 108: 296-297.

$\mathrm{Ng}, \mathrm{K} . \mathrm{T}$. and Gibbs, M.E. 1991. Stages in memory formation: A review. In: Neural and behavioural plasticity: The use of the domestic chick as a model (ed. R.J. Andrew), pp. 351-369. Oxford University Press, Oxford, UK.

O'Dell, T.J., Huang, P.L., Dawson, T.M., Dinerman, J.L, Snyder, S.H., Kandel, R.R., and Fishman, M.C. 1994. Endothelial NOS and the blockade of LTP by NOS inhibitors in mice lacking neuronal NOS. Science 265: 542-546.

O’Dowd, B.S., Gibbs, M.E., Sedman, G.L., and Ng, K.T. 1994a. Astrocytes implicated in the energizing of intermediate memory processes in neonate chicks. Cog. Brain Res. 2: 93-102.

O’Dowd, B.S., Gibbs, M.E., Ng, K.T., Hertz, E., and Hertz, L. 1994 b. Astrocytic glycogenolysis energizes memory processes in neonate chicks. Dev. Brain Res. 78: 137-141.

Prast, H. and Philippu, A. 2001. Nitric oxide as modulator of neuronal function. Prog. Neurobiol. 64: 51-68.

Prickaerts, J., Steinbusch, H.W.M., Smits, J.F.M., and de Vente, J. 1997. Possible role of nitric oxide-cyclic GMP pathway in object recognition memory: Effects of 7-nitroindazole and zaprinast. Eur. J. Pharm. 337: 125-136.

Rickard, N.S. and Gibbs, M.E. 2003. Effects of nitric oxide inhibition on avoidance learning in the chick are lateralized and localized. Neurobiol. Learn. Mem. 79: 252-256.

Rickard, N.S., Gibbs, K.T., and Ng, K.T. 1999. Endothelial, but not neuronal, nitric oxide synthase is required for passive avoidance learning in the day-old chick. Learn. Mem. 6: 458-466.

Rogers, L.J. and Deng, C. 1999. Light experience and lateralization of the two developing visual pathways in the chick. Behav. Brain Res. 98: 277-287.

Son, H., Hawkins, R.D., Martin, K., Kiebler, M., Huang, P., Fishman, M.C., and Kandel, E.R. 1996. Long-term potentiation is reduced in mice that are doubly mutant in endothelial and neuronal nitric oxide synthase. Cell 87: 1015-1023.

Stuehr, D.J., Fasehun, O.A., Kwon, N.S., Gross, S.S., Gonzalez, J.A., Levi, R., and Nathan, C.F. 1991. Inhibition of macrophage and endothelial cell nitric oxide synthase by diphenyleneiodonium and its analogs. FASEB J. 5: 98-103.

Zhang, H.W., Fast, W., Marletta, M.A., Martasek, P., and Silverman, R.B. 1997. Potent and selective inhibition of neuronal nitric oxide synthase by $\mathrm{N}^{\omega}$-propyl-L-arginine. J. Med. Chem. 40: 3869-3870.

Zou, L., Yamada, K., Tanaka, T., Kameyama, T., and Nabeshima, T. 1998. Nitric oxide synthase inhibitors impair reference memory formation in a radial arm maze task in rats. Neuropharmacol. 37: 323-330.

Received February 3, 2003; accepted in revised form August 1, 2003. 


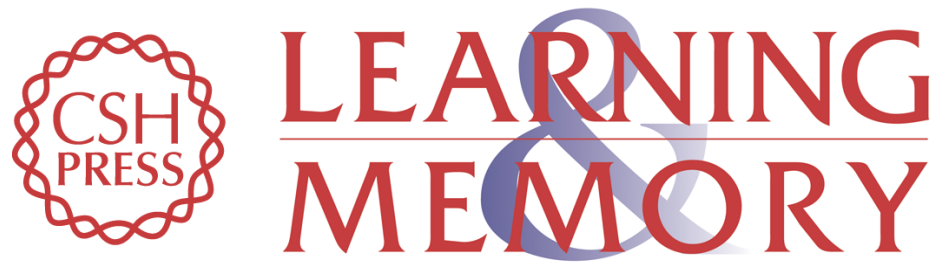

\section{Hemispheric Dissociation of the Involvement of NOS Isoforms in Memory for Discriminated Avoidance in the Chick}

Nikki S. Rickard and Marie E. Gibbs

Learn. Mem. 2003, 10:

Access the most recent version at doi:10.1101//m.59503

References This article cites 25 articles, 4 of which can be accessed free at:

http://learnmem.cshlp.org/content/10/5/314.full.html\#ref-list-1

License

Email Alerting Receive free email alerts when new articles cite this article - sign up in the box at the Service top right corner of the article or click here. 